DOI 10.31418/2177-2770.2020.v12.n.34.p358-378 | ISSN 2177-2770

Licenciado sob uma Licença Creative Commons

(2) $\frac{(1)}{\mathrm{N}}$

\title{
ESPACIO, GÉNERO Y RAZA: ESTRATEGIAS ESPACIALES DE RESISTENCIA AFRO-FEMENINA EN COLOMBIA
}

\author{
Lizeth Sinisterra Ossa ${ }^{1}$
}

\begin{abstract}
Resumen: Este artículo expone las estrategias espaciales de resistencias desarrolladas por las mujeres negras en Colombia, para contrarrestar las violencias que se experimentan en ciudades racializadas, empobrecidas y segregadas. Con base en un trabajo etnográfico realizado con diferentes lideresas sociales de la zona urbana de Buenaventura entre el 2018 y 2019, se busca visibilizar las respuestas colectivas de las mujeres negras para dignificar sus cuerpos, vidas y territorios. En este escenario, las mujeres más que victimas pasivas, son sujetas activas y capaces de resignificar sus encuentros con el poder hegemónico racista, sexista y capitalista que las subyuga. Esto nos permite reconocer y visibilizar el lugar político de las mujeres negras en una sociedad que las niega como sujetas y considera ciudadanas de tercera categoría.
\end{abstract}

Palabras-clave: Colombia, mujeres negras, violencia, geografía urbana y resistencias.

\section{ESPAÇO, GÊNERO E RAÇA: ESTRATÉGIAS ESPACIAIS DE RESISTÊNCIA AFRO-FEMININA NA COLÔMBIA}

Resumo: Este artigo expõe as estratégias espaciais de resistência desenvolvidas por mulheres negras na Colômbia, para combater a violência vivida em cidades racializadas, empobrecidas e segregadas. Com base no trabalho etnográfico realizado com diferentes líderes sociais da área urbana de Buenaventura entre 2018 e 2019, um objetivo é tornar visíveis as respostas coletivas das mulheres negras para dignificar seus corpos, vidas e territórios. Nesse cenário, as mulheres não são vítimas passivas, são sujeitos ativos e capazes de ressignificar seus encontros com o poder hegemônico racista, sexista e capitalista que as subjuga. $\mathrm{O}$ que permite reconhecer e tornar visível o lugar político das mulheres negras em uma sociedade que as nega como sujeitos e considera cidadãs de terceira categoria.

Palavras-chave: Colômbia, mulheres negras, violência, geografia urbana e resistencias.

\footnotetext{
${ }^{1}$ Docente e investigadora del Departamento de Estudios Sociales, Universidad Icesi (Colombia). Licenciada en Historia de la Universidad del Valle. Magíster en Estudios Sociales y Políticos de la Universidad Icesi. Becaria Especialización en Estudios Afrolatinoamericanos y Caribeños de CLACSO. E-mail: lizethsinisterra@gmail.com ORCID: https://orcid.org/0000-0003-1519-1746
} 


\begin{abstract}
This article exposes the spatial strategies of resistance developed by black women in Colombia to counteract the violence experienced in racialized, impoverished and segregated cities. Based on an ethnographic work carried out with different social leaders from the urban area of Buenaventura between 2018 and 2019, this article seeks to make visible the collective responses of black women to dignify their bodies, lives and territories. In this scenario, women, rather than passive victims, are active subjects capable of resignifying their encounters with the racist, sexist and capitalist hegemonic power that subdues them. In this way, the collective responses allow us to recognize and make visible the political place of black women in a society that denies them as subjects and considers third category citizens.
\end{abstract}

Keywords: Colombia, black women, violence, urban geography and resistances.

\title{
ESPACE, GENRE ET COURSE: STRATÉGIES SPATIALES DE RÉSISTANCE AFRO-FEMELLE EN COLOMBIE
}

Résumé: Cet article expose les stratégies spatiales de résistance développées par les femmes noires en Colombie, pour contrer la violence qui sévit dans les villes racialisées, appauvries et ségréguées. S'appuyant sur un travail ethnographique mené avec différents leaders sociaux de la zone urbaine de Buenaventura entre 2018 et 2019, l'objectif de cet article est de rendre visible les réponses collectives des femmes noires pour dignifier leur corps, leur vie et leur territoire. Dans ce scénario les femmes, plutôt que les victimes passives sont des sujets actifs et capables de résigner leurs rencontres avec le pouvoir hégémonique raciste, sexiste et capitaliste qui les soumet. Ce qui permet de reconnaître et de rendre visible la place politique des femmes noires dans une société qui les refuse comme sujets et considère les citoyens de troisième catégorie.

Mots-clés: Colombie, femmes noires, violence, géographie urbaine et résistances.

\section{INTRODUCCIÓN}

En Colombia, encontramos que hay vidas que tienen más valor que otras, en este caso, la vida negra es desvalorizada. Por ejemplo, muchos de los indicadores socioeconómicos que se encuentran más rezagados en el país están en territorios que concentra una alta población afrodescendiente, es decir, que esta población al comprarla con el resto de colombianos presenta una mayor brecha social, como es el caso de la región 
del Pacífico colombiano ${ }^{2}$; esto ha conllevado a un aniquilamiento físico, social y simbólico sobre los cuerpos negros. Esta región presenta uno de los mayores índices de pobreza (más del 60\%), y el índice de Necesidades Básicas Insatisfechas (NIB) es del 65, 17\%, una cifra superior a la registrada a nivel nacional con un 27,78 \% (PNUD, 2012). A esto se le suma, que las principales víctimas del conflicto armado en nuestro país han sido los grupos étnicos, particularmente las comunidades negras, como observamos en la Tabla 1.

\begin{tabular}{|c|c|c|c|c|c|}
\hline \multicolumn{6}{|c|}{ Tabla 1. Víctimas en Colombia con enfoque diferencial (1985 -2019) } \\
\hline Hecho & Indígena & $\begin{array}{c}\text { Gitano(a) } \\
\text { ROM }\end{array}$ & $\begin{array}{c}\text { Raizal (San } \\
\text { Andrés y } \\
\text { Providencia) }\end{array}$ & Palenquero & $\begin{array}{c}\text { Negro(a) } \boldsymbol{o} \\
\text { Afrocolombiano(a) }\end{array}$ \\
\hline Desplazamiento & 344.947 & 8.853 & 8.187 & 4.472 & $\mathbf{9 9 7 . 8 8 1}$ \\
\hline $\begin{array}{c}\text { Abandono o Despojo } \\
\text { Forzado de Tierras }\end{array}$ & 578 & 24 & 25 & 3 & $\mathbf{1 . 1 0 6}$ \\
\hline Homicidio & 16.401 & 420 & 2.951 & 200 & $\mathbf{4 2 . 9 2 3}$ \\
\hline $\begin{array}{c}\text { Perdida de Bienes } \\
\text { Muebles o Inmuebles }\end{array}$ & 6.998 & 32 & 587 & 80 & $\mathbf{1 4 . 8 7 3}$ \\
\hline Desaparición forzada & 3.858 & 90 & 291 & 45 & $\mathbf{9 . 5 8 9}$ \\
\hline Secuestro & 720 & 10 & 124 & 40 & $\mathbf{2 . 0 0 8}$ \\
\hline $\begin{array}{c}\text { Delitos contra la } \\
\text { libertad y la } \\
\text { integridad sexual }\end{array}$ & 1.473 & 12 & 49 & 26 & $\mathbf{5 . 6 5 9}$ \\
\hline $\begin{array}{c}\text { Acto } \\
\text { terrorista/Atentados/ } \\
\text { Combates/Hostigami } \\
\text { entos }\end{array}$ & 7.884 & 29 & 347 & 60 & $\mathbf{1 4 . 8 4 0}$ \\
\hline Amenaza & 23.954 & 138 & 447 & 333 & $\mathbf{5 9 . 8 4 5}$ \\
\hline
\end{tabular}

Fuente: elaboración propia a partir de datos del portal Registro Único de Víctimas (RUV) https://www.unidadvictimas.gov.co/es/registro-unico-de-victimas-ruv/37394

Estas cifras son un claro reflejo de la situación sistemática que deben enfrentar las comunidades negras en el país. Recordemos que la población negra inició su historia en Colombia y resto del mundo, desde la deshumanización, que conllevó a la negación plena de su humanidad, de su dignidad, de su libertad y de sus derechos fundamentales. Una realidad que no dista mucho de la actualidad, ya que el colonialismo junto con el racismo no es algo del pasado ya superado, sino un legado que sigue en muchos casos estructurando

\footnotetext{
${ }^{2}$ La región Pacífica se encuentra ubicada al occidente de Colombia y está conformado por los departamentos de Chocó, Valle del Cauca, Cauca y Nariño. Esta región se caracteriza por ser una de las zonas con mayor diversidad y riqueza ecológica, forestal, hidrográfica y minera del país; a su vez, por la confluencia de diversos grupos étnicos: los afrodescendientes equivalen el $90 \%$ del total de la población y los indígenas representan el 6\%, mientras que el $4 \%$ restante pertenece a la población mestiza (Centro Nacional de Memoria Histórica, CNMH, 2015).
} 
nuestro presente. Como bien lo expone Dayane Conceição de Assis (2017) para el caso brasileño:

A herança da escravização dos negros no Brasil possui traços marcantes na condição do negro na sociedade atual, a ocupação em subempregos, a baixa escolaridade em relação as demais populações, o índice de mortes alarmantes dos jovens são um dos inúmeros exemplos a serem citados, como já cantou uma belíssima voz negra: "A carne mais barata do mercado, é a carne negra." Além das sequelas mais visíveis, o racismo na sociedade brasileira assume outras formas por alguns considerados mais sutis que se utilizam do estigma para marcar e significar os corpos negros, e assim os conduzirem aos lugares sociais a ele pré-determinado (Conceição de Assis, 2017, p. 125).

Al igual que Brasil, en Colombia se ha instaurado una lógica "necro-política" que ha constituido unas zonas-antinegras que estructuran la distribución espacial de los cuerpos racializados y femeninos, y establece quién pertenece a la nación y quién no, quién tiene calidad de vida y quién no, quién vive y quién muere. Como bien lo expone Ariadna Estévez (2018) "las necropolíticas son tecnologías que pretenden organizar el espacio con base en raza, género y clase” (p. 6). En Colombia encontramos de esta manera, unas "geografías de muerte" (miseria, hambre, asesinatos, empobrecimiento, etc.), sustentadas y legitimadas tanto política como económicamente por el Estado, empresas transnacionales y grupos armados.

La constitución de las ciudades y los barrios en este país, permiten pensar la realidad del racismo estructural y la anti-negritud que opera en las instituciones y relaciones sociales en el mundo. En este sentido, la invisibilidad de la población negra y sus necesidades reales, sus derechos, etc. se incorporan a la forma urbana negra y reflejan parte de ese racismo estructural (CUNHA JUNIOR, 2019).

Toda esta violencia criminal, estatal y de mercado inmersa en contextos que concentra la gran mayoría de población negra en el país, como por ejemplo la región del Pacífico colombiano, son un dispositivo que "operativiza una serie de políticas cuyo fin es administrar la muerte de poblaciones consideras desechables para la reproducción del capitalismo neoliberal tanto legal como criminal, y las circunstancias políticas y sociales que lo sostienen” (ESTÉVEZ, 2018, p.1). 
Como bien lo señala Achille Mbembe (2003), la pobreza, la violencia, la muerte, la desigualdad, la privatización de la violencia y los mercados que amenazan la vida son fenómenos tan persistentes que lo que se regula y administra es la muerte. En este caso, en la región del Pacífico, el fin de la necropolítica es administrar y regular la muerte para asegurar la reproducción del capital criminal y legal. De esta manera, en Colombia, el capital necesita de la muerte para reproducirse y para ello, requiere vaciar los cuerpos y territorios. Por lo tanto, el racismo, el sexismo y el capitalismo se articulan para reproducir violencia, desigualdad, destierro y abandono. Por lo tanto, "la política de la raza esta en última instancia ligada a la política de la muerte” (MBEMBE, 2003, p. 22).

Esta práctica "necro-capitalista” como lo ha mencionado Bobby Banerjee (2008), ha operado a través del establecimiento de la soberanía colonial que se ha establecido en la economía política contemporánea, donde el negocio de la muerte puede tener lugar a través de Estados de Excepción. Estas prácticas le niegan a la población negra el acceso a recursos que son esenciales para su salud y vida, al destruir los medios de vida y desposeer a comunidades.

Por otro lado, en Colombia, el racismo - articulado con el sexismo y la clase socialproduce efectos violentos sobre las mujeres negras, ya que la cuestión racial y el género están conectados a la oportunidad ocupacional y las consecuencias de ubicar social y políticamente a las mujeres negras en el fondo de estas jerarquías de poder. Esto ha expuesto históricamente a las mujeres negras a trabajos devaluados, remuneración precaria, al empobrecimiento, la desigualdad socio-económica, feminicidios, entre otras formas de opresión (BRANCH, 2011).

En este sentido, varias reflexiones teóricas del feminismo negro contemporáneo señalan que la raza no es la única categoría de opresión y exclusión de las personas, sino que hay todo un aparato estructural donde las diferencias de clase, género, edad y sexualidad -entre otros ejes identitarios vistos desde una "matriz de dominación"constituyen distinciones de poder que refuerzan la desigualdad social, el racismo y el sexismo en nuestra sociedad (COLLINS, 1999; CRENSHAW, 1991).

En este país encontramos que las mujeres negras no tienen derecho a la ciudad. En las ciudades colombianas, las mujeres negras en su gran mayoría no cuentan con una vida digna, al goce pleno de derechos fundamentales (agua, salud, vivienda, educación, etc.) y a 
una real participación ciudadana en la construcción de la ciudad. Como bien lo expone Vicenta Moreno (2018) "el derecho a la ciudad no es únicamente la posibilidad de ocupar un espacio, sino de construirlo, participar y beneficiarse de todas las dinámicas que ofrece" (p. 82). No obstante, el Estado colombiano no reconoce los derechos colectivos en la ciudad y los proyectos urbanos obedecen a lógicas capitalistas, con el fin de aumentar el capital no de lograr un bienestar social y humano.

Dentro de este panorama, quedan inmersos los cuerpos de las mujeres negras, en este contexto, se necesita de la apropiación de los cuerpos racializados y femeninos para apropiarse de los espacios públicos y de lugares estratégicos dentro de la ciudad para el desarrollo de las economías legales e ilegales. No obstante, encontramos a un grupo de mujeres negras que subvierten estas políticas y economías de muerte, al transgredir múltiples espacios con sus cuerpos y vidas. Como se señaló en un principio, el objetivo central de este artículo es visibilizar las respuestas colectivas de las mujeres negras para dignificar sus cuerpos, vidas y territorios. En este escenario, las mujeres más que victimas pasivas, son sujetas activas y capaces de resignificar sus encuentros con el poder hegemónico racista, sexista y capitalista que las subyuga. En Colombia y en América Latina en general, encontramos grandes vacíos en la literatura que logre entender la relación entre mujeres negras, ciudad y resistencias. Por lo tanto, es importante que futuras investigaciones logren indagar más al respecto.

\section{BUENAVENTURA: UNA CIUDAD ANTI-NEGRA COLOMBIANA}

Si en Buenaventura, principal puerto de Colombia, todos fueran blancos, habría un desarrollo impresionante, pero donde están los negros no se puede invertir. (Michell, joven negra bonaverense, entrevista realizada el 15.08.18).

Buenaventura, localizada en el Pacífico Sur colombiano, se encuentra establecido el puerto marítimo más importante de Colombia en términos geoestratégicos (por su cercanía a Panamá, países de la región Asia-Pacífico y ciudades del este de los Estados Unidos). Allí se moviliza más del $50 \%$ de la actividad portuaria nacional, referida a la importación y exportación de mercancías. Según el Departamento Administrativo Nacional de Estadística 
(DANE), el 89\% de la población se auto-reconoce como negra o afrocolombiana, y el $92 \%$ reside en el área urbana.

Poblaba principalmente por negros, Buenaventura inmersa en la región del Pacífico colombiano, ha constituido según Almario (2009) una identidad acuática caracterizada por tener el mar al frente, los ríos atrás y la lluvia precipitándose sobre este territorio selvático. De acuerdo con el Plan de Ordenamiento Territorial, Buenaventura presenta una zona rural (compuesta por 19 corregimientos), y una zona urbana dividida en doce comunas (con aproximadamente 158 barrios), distribuidas en dos zonas: una insular (conocida también como isla Cascajal), donde se concentra gran parte de las actividades económicas y portuarias; y la zona Continental, que es predominantemente residencial (ALCALDÍA DE BUENAVENTURA, 2015).

En este territorio racializado, la combinación de patrones históricos de racismo, segregación espacial, empobrecimiento y la presencia de actores armados en la ciudad, han producido importantes grados de violencia contra la comunidad (Centro Nacional de Memoria Histórica, 2015). Por su conexión con múltiples lugares, esta ciudad es disputada y controlada por diversos actores legales e ilegales, para aprovechar rutas del narcotráfico y para el desarrollo de proyectos portuarios.

Aunque la actividad portuaria en Buenaventura da cuenta del crecimiento económico nacional, las condiciones de vida de su población negra sobresalen por la precariedad. En esta ciudad, la población negra está sometida a condiciones de vida que les confiere el estatus de estar "muertos social y simbólicamente" que les niega el derecho a la ciudad y a tener una vida digna: según cifras del DANE, el 66,5\% de la población se encuentran en condiciones de pobreza y el 36\% tiene alguna Necesidad Básica Insatisfecha (NBI). En su gran mayoría, la población no cuenta con agua potable, cobertura de acueducto ni alcantarillado, y la tasa de desempleo es del 62\% (Cámara de Comercio de Buenaventura, 2017).

Aquella parte de Buenaventura que no se encuentra social e institucionalmente incluida en la zona del puerto, ha venido enfrentando marcados procesos de exclusión social, económica y política. Es paradójico que mientras la Sociedad Portuaria de Buenaventura, puede acceder a todos los servicios públicos, el resto de la población no 
tiene acceso a agua potable y alcantarillado, ni existe un hospital con condiciones idóneas para atender a la población. Como bien lo expone una joven negra y habitante de la ciudad:

Buenaventura está en términos económicos, no en términos sociales. Así como el Estado busca un desarrollo económico en la región, también necesitamos que haya un desarrollo social en donde las personas tengamos la oportunidad de estudiar o de trabajar. Pero el Estado solo se centra en los puertos marítimos y la comunidad como tal queda excluida (Karen, joven negra bonaverense, entrevista realizada el 13.10.18).

Buenaventura se proyecta como unos de los puertos más importantes de Latinoamérica $^{3}$. Gran parte del auge de inversiones en la ciudad obedece a la necesidad del comercio internacional, lo que se materializa en profundas transformaciones para la configuración urbana sin traducirse en bienestar para el total de su población. La expansión portuaria genera la mayor parte del capital para los actores privados: el 83\% de participación en la Sociedad Portuaria la tienen empresarios nacionales e internacionales, controlada principalmente por el Grupo Parody, Grupo Harinera del Valle, TCBuen y Grupo Portuario S.A. Mientras que el $15 \%$ lo tiene el sector público, representado por la Alcaldía de Buenaventura y el 2\% le corresponde al Ministerio de Transporte. Estos actores privados no habitan en la región y no reinvierten en ella, produciendo un espacio social fracturado y desigual (VALENCIA, SILVA Y MORENO, 2016).

Varios de los proyectos portuarios en Buenaventura como la expansión de TCBUEN, han sido realizados sin el consentimiento y participación de la comunidad incluso generando amenazas y muertes a líderes y lideresas sociales que denuncian esta situación: uno de los casos que generó mayo conmoción en los habitantes fue el asesinato de Temístocles Machado en el año 2018, quien estaba resistiendo y luchando contra la ampliación portuaria en la comuna 6, los proyectos económicos de empresas multinacionales que invadían el territorio y la presencia de grupos armados en el desarrollo de las economías ilícitas (Comisión Intereclesial de Justicia y Paz-CIJP-, 2019; El Espectador, 2019).

\footnotetext{
${ }^{3}$ Actualmente, en la ciudad existen 8 proyectos que se enmarcan en el fortalecimiento de la logística portuaria: el Terminal de contenedores de Buenaventura (TcBuen), la Sociedad Puerto Industria Aguadulce, la ampliación del terminal actual, el muelle cementero, el Terminal Marítimo del Río Dagua (TMD), el proyecto CAEB (Centro de Actividades Económicas de Buenaventura), el proyecto Zelesa (Zona de Actividades Logísticas Extraportuarias de Buenaventura), y el proyecto CELPA S.A. (Centro Logístico del Pacífico S.A).
} 
Las comunidades negras que habitan lugares potenciales para el desarrollo de economías de actividades legales e ilegales, han sufrido por décadas procesos de desterritorialización al ser desplazadas violentamente dentro de la ciudad por los diferentes actores armados. Según la CIJP (2015):

Actualmente, los desplazamientos intra-urbanos e intermunicipales, las desapariciones forzadas, amenazas, homicidios, la violencia sexual y el reclutamiento forzado de niños, niñas y adolescentes se relacionan también como prácticas criminales vinculadas a la necesidad de liberar el territorio previsto en los planes de infraestructura del Distrito (p, 14).

Es así como para la población negra del puerto más importante del país, la lógica del desarrollo económico en Buenaventura "es sinónimo de muerte, de desplazamientos, de masacres, de despojo" (AMIRA, 2017). Un desarrollo que ha traído despojo, en medio además de la persistencia del conflicto armado y de la disputa que diversos actores armados hacen sobre la región, como una forma de vaciar el territorio.

Con los puertos privados en Buenaventura, las empresas que los controlan inician procesos de lo que denominaría David Harvey (2003) “acumulación por desposesión”, respaldados en la legitimidad que les brinda el Estado. En otras palabras, se prioriza la acumulación de capital, particularmente para grandes empresas, a costa de la desposesión de recursos naturales y territorios habitados por la población negra. Como lo plantea Almario (2004), en este territorio, se establece un nuevo modelo económico en el que se entrelazan algunos elementos del extractivismo salvaje del pasado junto con prácticas ilícitas, delincuenciales y paraestatales, articulando así las demandadas del capital transnacional. En este sentido, el puerto ha sido utilizado y saqueado por años, en él se instaló una conciencia colectiva utilitarista, que como expone el autor, ha reforzado la política local y nacional, que tienen en común el desprecio del entorno y de las comunidades.

En este sentido, como expone Olaya (2016), "la articulación entre el racismo, el despojo, el desplazamiento forzado y la economía contribuyen a la dispersión del fascismo social, definido como nuevas formas de dominación y explotación contemporánea para la producción y reproducción del capital". La violencia en la ciudad responde también a intereses políticos y económicos vinculados al desarrollo de los megaproyectos portuarios. 
Buenaventura por décadas es un ejemplo, como lo exponen Alves y Ravindran (forthcoming) de ser una zona anti-negra y en la cual se produce una lógica "necro(bio)política" del capitalismo contemporáneo, por su capacidad para producir valor de subyugación y muerte de cuerpos racializados.

Por lo tanto, en Buenaventura la población negra es devaluada, deshumanizada y explotada para satisfacer los intereses de las élites quienes establecen en la ciudad unas economías y políticas de muerte. Como bien lo plantea Mbembe (2003), el "necropoder" utiliza la violencia, la vulnerabilización de los cuerpos y la subyugación de la vida para crear más poder y riqueza concentrada en una minoría.

En síntesis, en Buenaventura, la población vive en medio de la pobreza, que, sumado a las disputas constantes entre diversos intereses, la corrupción y la convergencia de una serie de violencias producidas por actores armados, asociados principalmente a la expansión portuaria, al narcotráfico y a otras actividades criminales (minería, contrabando, extorsión, tráfico de armas, etc.), permiten caracterizar al distrito como uno que está inmerso en una serie de injusticias. En este escenario, es importante preguntarnos ¿cómo pensar una paz en medio de este contexto de pobreza y violencias permanentes?

\section{VIOLENCIA FEMINICIDA CONTRA LAS MUJERES NEGRAS}

Vivir en este territorio es como estar en medio de la guerra: la pobreza, la desigualdad social, la muerte y violencia han permanecido en nuestras vidas hace tiempo. (Darina, joven negra bonaverense, entrevista realizada el 25.09.18)

En Buenaventura se intersectan diversos factores de vulnerabilidad determinados por el género, la pertenencia étnica-racial y la condición social, que exponen a las mujeres negras a sufrir prácticas de violencia feminicida (asesinato, violencia sexual, destierro, etc.) desplegada por diversos actores (armados/ no armados), como se puede observar en la Tabla 2.

Tabla 2. Víctimas de violencia con enfoque diferencial en Buenaventura (1990 -2019) 


\begin{tabular}{|c|c|c|}
\hline Hecho & $\begin{array}{c}\text { Hombre } \\
\text { negro/afrocolombiano }\end{array}$ & $\begin{array}{c}\text { Mujer } \\
\text { negra/afrocolombiana }\end{array}$ \\
\hline Desplazamiento & 56.142 & 66.601 \\
\hline Homicidio & 1.412 & 2.021 \\
\hline $\begin{array}{c}\text { Perdida de Bienes Muebles } \\
\text { o Inmuebles }\end{array}$ & 412 & 730 \\
\hline $\begin{array}{c}\text { Acto terrorista/Atentados/ } \\
\text { Combates/Hostigamientos }\end{array}$ & 250 & 253 \\
\hline Amenaza & 2.909 & 3.079 \\
\hline
\end{tabular}

Fuente: Elaboración propia a partir de datos del portal Registro Único de Victimas https://www.unidadvictimas.gov.co/es/registro-unico-de-victimas-ruv/37394

De igual forma, el Instituto de Medicina Legal y Ciencias Forenses de Colombia reportó que entre 2009 y 2014 se presentaron 1.205 casos de violencia interpersonal contra mujeres; 2.070 mujeres fueron violentadas por sus parejas, y 121 niñas y adolescentes sufrieron violencia intrafamiliar. Durante este periodo, hubo 615 casos por delito sexual, y 707 mujeres fueron desaparecidas.

Estas cifras se suman a la muerte social de las mujeres negras, representada por una violencia estructural inmersa en la ciudad por décadas: según el Ministerio de Trabajo y USAID, la pobreza en Buenaventura está concentrada principalmente en las mujeres y su acceso al mercado laboral es limitado ${ }^{4}$. Como se demuestra también en estudios realizados por la Secretaria Distrital de Salud de Buenaventura (2017), se encuentra que la tasa de mortalidad materna en esta ciudad es la más alta de Colombia. ${ }^{5}$

También, Buenaventura se encuentra entre los municipios del país, que presenta una de las cifras más altas en embarazos adolescentes entre los 10 y 14 años de edad (Instituto Colombiano de Bienestar Familiar, 2015), esto se debe en gran parte a la falta de oportunidades educativas, además, las mujeres jóvenes no cuentan con un centro sobre salud sexual y reproductivo, como es el caso de Profamilia que fue cerrada hace unos años en la región, y que presta diversos servicios como es el caso de uso de método anticonceptivos, aborto seguro, vacunación, fertilidad, ginecología, etc.

\footnotetext{
${ }^{4}$ Buenaventura, ciudad Puerto de clase mundial. Plan Local de Empleo 2011-2015. Informe realizado por el Ministerio de Trabajo, Programa de Atención a desplazados y grupos vulnerables. USAID.

${ }^{5}$ Durante el periodo de 2005 a 2015 la Razón de Mortalidad Materna (RMM) de Buenaventura ha sido superior a la RMM registrada a nivel nacional; las RMM más alta se registraron en el año 2005 en donde se presentaron aproximadamente 201 muertes maternas por cada cien mil nacidos vivos y en el año 2015 con una RMM de 260 muertes maternas por cada cien mil nacidos vivos.
} 
Para Ana, una joven negra y habitante de Buenaventura, en esta ciudad existe un sistema patriarcal y racista, el cual, como expone ella "ejerce un poder sobre nosotras, que nos condena a estar por debajo de una línea de inferioridad, donde nos deshumaniza y no nos permite llevar una vida normal como cualquier otra mujer" (Ana, joven negra bonaverense, entrevista realizada el 31.12.18).

En Buenaventura, las mujeres negras están limitadas al pleno goce de sus derechos; siguen siendo víctimas de múltiples formas de exclusión y violencia estatal, sexista, racista y capitalista. Como bien lo señalan Moreno y Mornan (2015):

El Estado racial y patriarcal ha imperado de manera brutal sobre el cuerpo de las mujeres negras negando posibilidades de salud, oportunidades educativas y económicas además de patrocinar la explotación y manipulación del mercado laboral, el narcotráfico y las dinámicas de guerra que las afectan de sobremanera ( $\mathrm{p}$, 105).

Las violencias contra las mujeres negras constituyen una manifestación de relaciones de poder desiguales entre hombres y mujeres, las cuales han generado la opresión, dominación y discriminación de este grupo poblacional, que para el caso de mujeres racializadas se articula con los estereotipos étnico/raciales que las ponen en una posición de desventaja.

En este escenario, los feminicidios y demás formas de violencia contra las mujeres negras en Colombia, deben entenderse como una estrategia de terror que busca vaciar el territorio y los cuerpos (Lozano, 2016; Ramírez, 2017). En otras palabras, el cuerpo racializado y femenino es visto como un instrumento de la guerra, en el cual está inmerso en las complejas economías legales e ilegales de Buenaventura.

Este es el caso de mujeres negras que denuncian a empresas transnacionales que producen violencia, muerte y destierro a la población, como una forma de vaciar el territorio y poder expandir el puerto, este es el ejemplo de TCBuen, una empresa catalana que ha vulnerado los derechos humanos de muchos de los habitantes del territorio. Mujeres como Leyla Arroyo y Danelly Estupiñan, lideresas de Buenaventura pertenecientes al Proceso de Comunidades Negras y a la mesa del Paro Cívico, ellas han sufrido amenazas a partir de sus denuncias por las afectaciones que causan los proyectos de expansión 
portuaria (El Espectador, 2019). Por lo tanto, se requiere de la eliminación de la población para liberar y controlar nuevos espacios para la acumulación del capital.

Por lo tanto, en este contexto que presenta múltiples conflictividades, los cuerpos de las mujeres negras se convierten en un dispositivo de poder, dominación y control de los territorios no solo por parte de los actores criminales para desarrollar y expandir las economías ilegales, sino también por el capital transnacional.

\section{MUJERES NEGRAS: DIGNIFICANDO VIDA, CUERPOS Y TERRITORIOS}

Las mujeres negras en Buenaventura están limitadas al pleno goce de sus derechos y son víctimas de múltiples formas de exclusión y violencia estatal, sexista, racista y capitalista. Frente a esta situación, se han organizado para ejercer resistencias y reexistencias. Históricamente, desde nuestra Amefrica (concepto establecido por la brasileña Léila Gonzales), se vienen agenciando distintas luchas enmarcadas en el campo de los feminismos negros. Como bien lo expone Campoalegre (2018), el movimiento de mujeres negras en estos países viene conquistando espacios importantes y ganando protagonismo en la lucha contra las estructuras sociales, políticas y culturales que sostienen el racismo y la discriminación en nuestros países.

En nuestra región, las mujeres negras han ocupado un lugar destacado en el movimiento afrodescendiente y organizaciones colectivas. Han conquistado espacios importantes y han ganado protagonismo en diferentes luchas antirracistas y anticoloniales. En este caso, las mujeres negras de Buenaventura, ven en la organización social y colectiva una forma de luchar y resistir ante las opresiones múltiples y simultaneas que se entretejen contra sus vidas y cuerpos racializados, mostrando la necesidad de pasar y visibilizar ello al terreno político.

Las mujeres negras en esta ciudad, aparecen en este contexto como sujetas políticas que usan su identidad para resignificar su experiencia y vivir urbano, realizando una lucha política por los derechos a la ciudad, a la vida y a la dignidad. Estas mujeres sobreviven y transgreden múltiples espacios a través de prácticas ancestrales que usan como una forma 
de resistir y contrarrestar las violencias. Mujeres que ayudan a preservar la memoria que ha sido abatida producto de las guerras y conflicto armado.

Aquí la memoria entra en un campo de disputa política, en el cual las narrativas oficiales o memorias hegemónicas del conflicto, que además de invisibilizar las experiencias vividas de victimización, es retada por las "memorias subterráneas" de las mujeres negras, para quienes el vivir urbano es un recuerdo constante de su no-lugar en la sociedad. Estas memorias emergen y encuentran canales de difusión alternativos a los canales institucionalizados, a través del arte, las letras, la música, el canto, etc.

En este lugar, las mujeres negras mediante diversas estrategias de resistencia se enfrentan a actores armados, narcotraficantes, paramilitares y policías, que en conjunto trazan fronteras de muerte para ellas y muchos jóvenes negros. También las mujeres se enfrentan a despojos y destierros violentos producto del ordenamiento territorial y por proyectos de expansión portuaria establecido por el Gobierno y empresas transnacionales, los cuales desalojan a las poblaciones de sus territorios para implantar sus modelos de desarrollo. Los feminicidios, estereotipos, la falta de oportunidades educativas, la explotación laboral, son otras de las violencias cotidianas a las que se enfrentan las mujeres negras en este territorio. Estas violencias ejercidas contra ellas es un ejercicio sistémico y múltiple de interseccionalidad, que tiene un vínculo directo con el lugar histórico que el patriarcalismo, capitalismo y el racismo ha dado a los cuerpos negros y femeninos.

Pese a todas las formas de injusticias (espacial, racial y de género) establecidas en Buenaventura, las mujeres reconstruyen alternativas de vida, creando lazos de solidaridad, recreando las calles mediante la ancestralidad; propiciando espacios de conversación, lucha y construcciones colectivas. Mujeres que, desde la segregación y exclusión social, desarrollan unas "geografías de oposición", resistencias y re-significación de las realidades que viven. Estas estrategias de resistencias que construyen las mujeres negras son para enfrentar la marginalidad política y violencias que se entretejen sobre sus cuerpos, vidas y territorio. Estas mujeres convierten a Buenaventura, también un lugar de esperanzas, sueños y construcción de vida.

En este sentido, de ese ciclo de violencias en las que han estado inmersas, nacen organizaciones y redes de mujeres negras que promueven la resistencia a través de procesos de denuncia, reapropiación y defensa de su territorio, recuperación de prácticas ancestrales, 
ya que como lo manifiesta una de las integrantes del Colectivo WIWA "las mujeres negras estamos construyendo paz desde nuestro cuerpos y vidas. Las mujeres negras de Buenaventura construimos paz de adentro hacia afuera" (OLIVIA, entrevista realizada el 30.11.19).

En medio de este escenario surgen estrategias colectivas de mujeres negras que hacen una lectura de su realidad, generando así herramientas para contrarrestar toda forma de violencias contra ellas. Así, el movimiento de mujeres en el Distrito de Buenaventura ha crecido no solo en número sino en unidad de sentir, de pensar e incidir a favor de las causas que las atañen y en las estrategias para enfrentar el feminicidio, generando lazos de hermandad y de articulación para lograr un bien común. Así lo expresa una mujer negra y lideresa social de la región: "las mujeres de Buenaventura empezamos a dejar de vernos como esclavas modernas en el ejercicio de sus roles, para concebirnos como mujeres con un alto nivel de resiliencia y liderazgo" (KAREN, entrevista realizada el 24.10.19)

Muchas de las prácticas que realizan las redes de mujeres negras, son formas de sanar, agenciar, tramitar el sufrimiento y el dolor por medio de toda clase de expresiones: poesía, recuperación de la ancestralidad, arte, canto, etc. Son mujeres que desde el abajo están haciendo algo por sus comunidades y territorios racializados, empobrecidos y segregados. Como bien lo exponen Moreno y Mornan (2015): "las mujeres negras subvierten las lógicas espaciales de opresión y diseñan posibilidades para una lucha política por el derecho a la ciudad" (p, 106). Estas acciones permiten reconocer y visibilizar el lugar político de las mujeres negras en una sociedad que las niega como sujetas y las considera ciudadanas de tercera categoría. De ahí que sea importante visibilizar las narrativas y la lucha de los cuerpos negros y sexualizados ante la colonialidad del poder, saber, ser y género.

Por ejemplo, una de las estrategias espaciales de resistencia realizadas por las mujeres es la recuperación del espacio público a través de la ancestralidad, lugares que han sido tomados por grupos armados y que no permiten que los habitantes puedan usarlos. Estas acciones se convierten en signos políticos para la reivindicación del derecho al territorio. Un ejemplo de ello, se puede encontrar en la historia de Ángela, una mujer negra "cantaora", que le negaron el derecho a pasar a otro barrio a velar a un familiar que fue 
asesinado y decidió recorrer las calles cantando para poder hacer resistencia frente a esos que le dijeron "no pueden cruzar, no pueden pasar".

Otra estrategia fue la ocupación de las calles durante el Paro Cívico en el año 2017, por parte de las mujeres que expresaron su disgustado al no vivir en una ciudad digna y que buscaba declarar la emergencia social, económica y ecológica de Buenaventura. Con el lema "las mujeres no se rinden carajo", ellas se sumaron a la lucha y tuvieron una participación activa en las calles y en las mesas de dialogo con el Gobierno Nacional. Por lo tanto, las mujeres marcharon en busca de una justicia social, espacial, racial y de género.

También a través de la poesía, muchas mujeres negras plasman sus miedos y alegrías, desafiando las violencias. A través de sus letras, ponen en juego sus resistencias y experiencias de vida:

\section{No te rindas}

... No te rindas mujer valiosa, porqué tus sueños vas a lograr.

Entierra tus miedos para así luchar

Retomar el vuelo para brindarnos una oportunidad

Donde no haya jerarquía para nuestra comunidad.

¡No te rindas!

Para lograr un movimiento social de libertad

Con autonomía epistémica y descolonización de nuestra

sociedad.

Para construir nuestro conocimiento ya

¡No te rindas!

Para hacer realidad nuestra a utopía aquí y ahora

¡No te rindas!

Mujer comprometida, esta es la hora y el mejor momento

para obtener la libertad.

¡No te rindas...!

(Red de Mujeres del Pacífico)

De esta manera, desde el movimiento de mujeres negras en Buenaventura se ha avanzado mucho desde las colectividades, liderazgos y organizaciones. A través de sus apuestas han posibilitado que otras mujeres y jóvenes del territorio logren empoderarse y encontrar otras oportunidades que el mismo Estado no les ha brindado. Son mujeres que desde su accionar buscan dar solución a las problemáticas de su entorno social; son capaces de producir respuestas a los desafíos que se generan en sus contextos. Raramente ellas 
aparecen como sujetas políticas capaces de producir respuestas autónomas a los desafíos urbanos. Sin embargo, como exponen Riaño (2000) y Ortiz (2013) las zonas marginales de las ciudades latinoamericanas (y colombianas en este caso) son laboratorios de resistencia, resiliencia e innovación social.

Estas mujeres negras comparten una historia de opresión/dominación contra nuestros cuerpos sexuados y racializados, pero también que cuenta con redes afrofeministas que han constituido una agenda contra-hegemónica y movilizadora frente a esas violencias sistemáticas, múltiples y cotidianas que se han anclado contra nuestra población negra. Mujeres negras que luchan por una justicia y autonomía política en su territorio, que ha estado atravesado por políticas y economías de muerte.

Las mujeres negras lo hacen a través del trabajo comunitario, de la re-significación de sus cuerpos con derechos y herencia ancestral y sinergias diaspóricas. Sus acciones están modificando y generando realidades otras que sí consideran a las mujeres negras como sujetas de derechos. Estas redes construidas responden a una generación de pedagogías de mujeres negras cimarronas, las prácticas desarrolladas de forma colectiva, con compromiso, ancestralidad y constante resistencia genera una dinámica propia de pedagogías, desde el ser y sentir como mujeres racializadas e hipersexualizadas. Este aporte significa la reexistencia de mujeres negras como sujetas políticas, académicas e intelectuales, determinan el pensamiento contrahegemónico que tanta falta le hace a la academia y sectores políticos en nuestros países. Definitivamente las acciones y respuestas desde las practicas articuladas de las mujeres negras van demarcando las formas de reestructurar las sociedades fundadas en bases coloniales, raciales, sexistas, patriarcales, hetero-normativas y clasistas.

\section{CONCLUSIONES}

A pesar del escenario conflictivo en que se encuentran muchas mujeres negras que son víctimas en Buenaventura, ellas dan un vuelco a su realidad, son mujeres activas y empoderadas. Algunas de las acciones que las mujeres desarrollan para contrarrestar las violencias, son signos políticos de lucha por el derecho a la ciudad, a la vida y dignidad.

En el contexto actual de postacuerdo que vive Colombia son muchos los desafíos que quedan. Se debe tratar de garantizar la ausencia de todo tipo de violencias: directa 
(violencia física), estructural (desigualdad, pobreza, marginación, etc.) y cultural/simbólica (machismo, homofobia, intolerancia, racismo, etc.), que posibilite el bienestar social y desarrollo humano en ciudades racializadas y empobrecidas, como es el caso de Buenaventura. Es urgente y necesario poner atención a las mujeres urbanas víctimas de la guerra ordinaria y de la violencia estructural de las urbes colombianas. De igual manera, se debe reconocer y visibilizar la agencia de las mujeres negras, que ha llevado a una estrategia política de retar también los estereotipos que hay sobre ellas mismas y de reinventar el territorio como un espacio de paz.

Desde la academia colombiana se están propiciando herramientas para descubrir voces, silencios y resistencias desde las afrodescendencias, esto con el fin de seguir cuestionando las lógicas y prácticas racistas, sexistas y machistas que han sido monopolizadas y en algunos casos naturalizadas desde este espacio. Es por esto, que desde diferentes frentes se construyen espacios para evidenciar y visibilizar nuestras voces, desde nuestro lugar de enunciación decidimos escribir e investigar nuestra propia historicidad, nuestras propias vivencias y la de otros.

Como bien lo exponen Miranda et al., (2019) y Ocoró (2019), combatir el racismo, el eurocentrismo y el colonialismo desde nuestra actividad académica es un camino para la construcción de una justicia social y el reconocimiento de nuestros pueblos y de nuestra ancestralidad. En este sentido, los/as investigadores/as negros/as tenemos la responsabilidad histórica de contribuir a construir, difundir, problematizar y cuestionar el conocimiento que se da sobre la realidad social y cultural de las poblaciones negras o afrodescendientes de América Latina y del Caribe.

A pesar de este racismo institucional y epistémico que sigue prevaleciendo en la académica, los/las investigadores/as negros/as están contribuyendo desde este campo a formular proyectos políticos epistémicos contrahegemónicos, los cuales señalan la responsabilidad de construir y difundir el conocimiento sobre la realidad social y cultural de las poblaciones negras de esta región. Como bien lo expone Campoalegre (2019), "nada mejor que adentrarse en un campo invisibilizado como el pensamiento negro, para obtener nuevos enfoques y respuestas alternativas", por lo tanto, ganar espacios de participación desde la formación, la enseñanza y la academia permite contar otro tipo de historias, vivencias, experiencias y formas de ver y actuar frente al mundo. 


\section{REFERENCIAS}

ALMARIO, Oscar. De lo regional a lo local en el Pacífico Sur colombiano, 1780 - 1930. HiSTOReLo, v. 1, n. 1, 2009, p. 76-129.

ALMARIO, Oscar. Dinámica y consecuencias del conflicto armado colombiano en el Pacífico: limpieza étnica y desterritorialización de afrocolombianos e indígenas y 'multiculturalismo' de Estado e indolencia nacional. En: RESTREPO, Eduardo y ROJAS, Axel. Conflicto e (in)visibilidad: Retos en los estudios de la gente negra en Colombia. Popayán: Editorial Universidad del Cauca, 2004.

ALVES, Jaime y RAVINDRAN, Tathagatan. Racial capitalism, the Free Trade Zone of Pacific Alliance, and Colombian Utopic Spatialities of Anti-Blacknees. ACME: An International Journal for Critical Geographies (Forthcoming).

ALCALDÍA DE BUENAVENTURA. Plan de ordenamiento territorial (POT). Convivencia Pacífica desde la Diversidad, 2015. Disponible en: http://www.buenaventura.gov.co/images/multimedia/resumen_ejecutivo_-_pot_2013.pdf. Acceso: 5 de enero de 2020.

AMIRA, Rossih. El paro cívico en Buenaventura muestra la otra cara del "desarrollo". Disponible en: $\quad$ https://colombiaplural.com/paro-civico-buenaventura-muestra-la-otra-cara-del-desarrollo/. Acceso: 15 de enero de 2020.

BANERJEE, S. B. Necrocapitalism. Organization Studies, v. 29, n. 12, 2008, pp. 1541-1563.

BRANCH, Enobong. Opportunity Denied. Limiting Black Women to Devalued Work. New Jersey: Rutgers University Press, 2011.

CÁMARA DE COMERCIO DE BUENAVENTURA. Análisis socioeconómico de Buenaventura, $2017 . \quad$ Disponible en: https://www.ccbun.org/images/multimedia/20180131_analisis_socioeconomico_del_distrito_de_bu enaventura 2017.pdf. Acceso: 20 de noviembre de 2019.

CAMPOALEGRE, Rosa. Una escuela tan negra como nosotras: desafíos ante el racismo y el patriarcado. Praxis Educacional, v. 15, n 32, 2019, p. 17-32.

CAMPOALEGRE, Rosa. Feminismos negros en clave descolonial: Enfoques, tensiones y futuros desde Cuba. Disponible en: www cubainformatv. Acceso: 10 de enero de 2020.

CENTRO NACIONAL DE MEMORIA HISTÓRICA. Buenaventura: un puerto sin comunidad. Bogotá: CNMH, 2015.

COLLINS, Patricia Hill. Moving beyond gender: Intersectionality and scientific knowledge. In FERREE, Myra Marx, LORBER, Judith y HESS, Beth B. Revisioning Gender. New York: Altamira Press, 1999.

CONCEIÇÃO DE ASSIS, Dayane. corpos negros e representação social no Brasil: uma discussão de gênero e raça. Revista da $A B P N$, v. 9, n. 21, 2017, pp. 123-134. 
COMISIÓN INTERECLESIAL DE JUSTICIA Y PAZ. Temístocles Machado. Disponible en: https://www.justiciaypazcolombia.com/temistocles-machado/. Acceso: 12 de enero de 2020.

COMISIÓN INTERECLESIAL DE JUSTICIA Y PAZ. Buenaventura. El despojo para la competitividad, 2015. Disponible en: http://www.mundubat.org/wpcontent/uploads/2016/03/BuenaventuraInprenta.pdf. Acceso: 8 de agosto de 2019.

CRENSHAW, Kimberlé. Mapping the margins: Intersectionality, identity politics, and violence against women of color. Stanford Law Review, v. 43, n. 6, 1991, pp.1241-1299.

CUNHA JUNIOR, Henrique. Bairros negros: a forma urbana das populações negras no Brasil. Revista da ABPN, v. 11, 2019, pp. 65-87.

El Espectador. La lucha de Temístocles Machado: más viva que nunca. Disponible en: https://www.elespectador.com/colombia2020/justicia/verdad/la-lucha-de-temistocles-machado-masviva-que-nunca-articulo-857588. Acceso: 26 de septiembre de 2019.

El Espectador. Las ansias de justicia son superiores a los riesgos: Lideresa de Buenaventura amenazada. Disponible en: https://www.elespectador.com/colombia2020/territorio/las-ansias-dejusticia-son-superiores-los-riesgos-lideresa-de-buenaventura-amenazada-articulo-857644. Acceso: 7 de mayo 2019.

ESTÉVEZ, Ariadna. El dispositivo necropolítico de producción y administración de la migración forzada en la frontera Estados Unidos-México. Estudios Fronterizos, v. 19, 2018, pp. 1-18.

GONZALEZ, Léila. A categoria político-cultural de amefricanidade. Tempo Brasileiro, n. 92/93, 1988, p. 69-82.

HARVEY, David. El nuevo imperialismo. Madrid: Ediciones Akal, 2003.

INSTITUTO COLOMBIANO DE BIENESTAR FAMILIAR. Embarazo en adolescentes: Generalidades y percepciones, 2015. Disponible en: https://www.icbf.gov.co/sites/default/files/embarazo-adolescente-web2015.pdf. Acceso: 2 de octubre de 2019.

LOZANO, Betty Ruth. Tejiendo con retazos de memorias insurgencias epistémicas de mujeres negras/afrocolombianas. Aportes a un feminismo negro decolonial. Tesis Doctorado. Ecuador: Universidad Andina Simón Bolívar, 2016.

LUGONES, Maria. Hacia un feminismo descolonial. La manzana de la Discordia, v. 6, n. 2, 2011, p. 105-119.

MBEMBE, Achilles. Necropolitics. Public Culture, v. 15, n. 1, 2003, p. 11-40.

MIRANDA, Claudia, et al. Presença de mulheres negras na pesquisa em educação: conversas sobre o estágio docente. Praxis Educacional, v. 15, n. 32, 2019, p. 132-154. 
MORENO, Vicenta y MORNAN, Debaye. ¿Y el Derecho a la Ciudad? Aproximaciones sobre el racismo, la dominación patriarcal y estrategias feministas de resistencia en Cali, Colombia. Revista CS 16, n. 16, 2015, p. 87-108.

MORENO, Vicenta. Entre la dignidad y la muerte: mujeres negras, dominación patriarcal y estrategias espaciales de resistencia en un barrio popular de Santiago de Cali. Tesis de Maestría. Colombia: Universidad del Valle, 2018.

OCORÓ, Anny. Emancipación y descolonización: tensiones, luchas y aprendizajes de los investigadores/as negros/as en la educación superior. Praxis Educacional, v. 15, n. 32, 2019, p. 5368 .

OLAYA, Angela. La racialización del despojo: territorios y migración forzada de pueblos afrodescendientes en el Pacífico colombiano. Revista GeoNordeste, n. 2, 2016, p. 35-48.

ORTIZ, Nicolás. Producción de sentidos en jóvenes de organizaciones juveniles del municipio de Santiago de Cali, Colombia. PROSPECTIVA, n. 17, 2013, p. 115-140.

RAMÍREZ, Danny. Feminicidios en las economías criminales de Buenaventura. Tesis Maestría. Bogotá: Universidad Nacional de Colombia, 2017.

RIAÑO, Pilar. ¿Por qué a pesar de tanta mierda este barrio es poder? Historias locales a la luz nacional. Revista Colombiana de Antropología, n. 36, 2000, p. 50-83.

SECRETARIA DISTRITAL DE SALUD. Análisis de Situación de Salud Modelo de los Determinantes Sociales de Salud Distrito de Buenaventura, 2017. Disponible en: https://www.minsalud.gov.co/sites/rid/Lists/BibliotecaDigital/RIDE/VS/ED/PSP/asis-distrital2017-buenaventura.pdf. Acceso: 18 de octubre de 2019.

VALENCIA, Inge Helena, SILVA CHICA, Laura y MORENO, Alejandro. Violencia, desarrollo y despojo en Buenaventura. Análisis, n. 9, 2016, p. 1-18.

Recebido em: 22/09/2020

Aceito em: 30/10/2020 